\title{
Effect of parathyroid hormone on early chondrogenic differentiation from mesenchymal stem cells
}

Yun Zhang, Ken Kumagai ${ }^{*}$ and Tomoyuki Saito

\begin{abstract}
Background: Treatment of articular cartilage injuries remains a difficult challenge due to the limited capacity for intrinsic repair. Mesenchymal stem cells (MSCs) can differentiate into chondrocytes under certain culture conditions. This study focused on the modulatory effects of parathyroid hormone (PTH) on chondrogenic differentiation from MSCs.

Methods: MSCs were treated with various concentrations of PTH under chondrogenic pellet culture condition. RNA was isolated for real-time polymerase chain reaction (PCR) and gene expressions of collagen type II a1 chain (Col2a1), collagen type X a1 chain, collagen type I a1 chain, SRY-box9 (Sox9), and type 1 PTH/PTHrP receptor (PTH1R) were examined. Chondrogenic differentiation was also evaluated by histological findings.

Results: PTH had opposite effects on chondrogenesis, depending on the concentration. A low to moderate concentration of PTH promoted chondrogenic differentiation of MSCs with increased expression of Sox9, Col2a1, and PTH1R, whereas chondrogenesis of MSCs was inhibited rather than stimulated with a higher concentration of PTH.

Conclusion: This study provides insights into the modulatory effect of PTH on chondrogenic differentiation from MSCs and the therapeutic potential for cartilage regeneration. Based on clinical experience regarding the efficacy and safety of PTH for bone metabolism, PTH may also be useful clinically for cartilage repair.
\end{abstract}

Keywords: Parathyroid hormone, Chondrogenic differentiation, Mesenchymal stem cells

\section{Background}

Treatment of articular cartilage injuries remains a difficult challenge due to the limited capacity for intrinsic repair. Tissue engineering approaches have been introduced as treatment options for cartilage repair. Treatment efficacy depends entirely on the cells in the grafted site, particularly the small subset of stem and progenitor cells that are capable of generating new tissue [1]. Thus, cell-based approaches are key to successful tissue engineering [2].

Mesenchymal stem cells (MSCs) are the most commonly used cell source with a high self-renewal capacity, multilineage potential, and easy isolation from several human tissues including bone marrow [3,4]. MSCs can differentiate into chondrocytes under certain culture conditions $[5,6]$ and have been used for cartilage regeneration

\footnotetext{
* Correspondence: kumagai@yokohama-cu.ac.jp Department of Orthopaedic Surgery and Muscloskeletal Science, Graduate School of Medicine, Yokohama City University, 3-9 Fukuura, Kanazawa-ku, Yokohama 236-0004, Japan
}

medicine by many researchers $[7,8]$. Therefore, a number of research efforts are directed to the isolation of progenitor cells and the understanding of the mechanisms involved in their chondrogenic differentiation.

Parathyroid hormone (PTH) is known as an 84-amino acid protein that regulates bone remodeling and calcium homeostasis. When PTH is administrated intermittently as a pharmacological agent, exogenous PTH has been shown to exert significant anabolic effects. Several studies indicated that $\mathrm{PTH}(1-34)$ also affects chondrocyte. PTH(1-34) inhibits the terminal differentiation of archondrocytes and the progression of osteoarthritis $(\mathrm{OA})[9,10]$. In parallel with the suppression of chondrocyte hypertrophy, $\mathrm{PTH}(1-34)$ stimulates chondrocyte proliferation and differentiation in the early stage [11-15]. However, the effects of PTH on chondrogenic differentiation of MSCs remain to be elucidated. We hypothesized that PTH promotes early chondrogenic differentiation from MSCs. Here, we show the 
investigation of the modulatory effect of PTH on chondrogenic differentiation from MSCs.

\section{Materials and methods Culture of MSCs}

Murine bone marrow-derived MSCs (Cyagen Biosciences, Santa Clara, CA, USA) were expanded in a monolayer culture with mesenchymal stem cell growth medium (GUXMX-90011, Cyagen Biosciences) supplemented with $10 \%$ fetal bovine serum, 100 units $/ \mathrm{mL}$ penicillin, $100 \mu \mathrm{g} / \mathrm{mL}$ streptomycin, and glutamine at $37^{\circ} \mathrm{C}$ with $5 \% \mathrm{CO}_{2}$ until the cells reached $80 \%$ confluence. The cells were then trypsinized and frozen in liquid nitrogen for later use. After thawing and monolayer expansion, cells at passage 5 or 6 were harvested and subjected to pellet formation and chondrogenic differentiation.

\section{Induction of chondrogenic differentiation and PTH administration}

Pellets of $2.5 \times 10^{5}$ MSCs were formed by centrifugation at $200 \mathrm{~g}$ for $5 \mathrm{~min}$ in $15-\mathrm{mL}$ centrifuge tubes or $1.5-\mathrm{mL}$ microcentrifuge tubes. After incubation at $37^{\circ} \mathrm{C}$ in $5 \%$ $\mathrm{CO}_{2}$ for 4 days, pellets were transferred to 96-well Ubottomed plates. Cells were exposed to chondrogenic medium (high-glucose DMEM with $0.1 \mu \mathrm{M}$ dexamethasone, $0.17 \mathrm{mM}$ ascorbic acid-2 phosphate, $5 \mu \mathrm{g} / \mathrm{mL}$ insulin, $5 \mu \mathrm{g} / \mathrm{mL}$ transferrin, $5 \mathrm{ng} / \mathrm{ml}$ selenous acid, $0.35 \mathrm{mM}$ L-proline, 100 units $/ \mathrm{mL}$ penicillin, and $100 \mu \mathrm{g} / \mathrm{mL}$ streptomycin) supplemented with $10 \mathrm{ng} / \mathrm{mL}$ transforming growth factor- $\beta 3$ (TGF- $\beta 3$ ). To detect the concentration dependency of PTH(1-34) treatment of TGF- $\beta$-driven chondrogenesis, TGF- $\beta$-enriched chondrogenic medium was supplemented with different concentrations of PTH (0.1, $1,10$, and $100 \mathrm{nM})$. The medium was changed every 2 or 3 days. Chondrogenic pellets were harvested at 3, 7, or 21 days.

\section{Histological analyses}

After 3 weeks of culture, pellets were fixed overnight at $4^{\circ} \mathrm{C}$ in $4 \%$ paraformaldehyde solution, dehydrated with ethanol, washed with xylene, and embedded in paraffin. Sections at $5 \mu \mathrm{m}$ thickness were cut from the paraffin blocks and mounted on glass slides. The sections were deparaffinized with xylene and ethanol prior to staining. To detect proteoglycan synthesis as an indicator of cartilage production, the sections were stained with Alcian Blue according to the standard protocol. For immunohistochemical staining of collagen type II, the sections were treated with $1 \mathrm{mg} / \mathrm{ml}$ hyaluronidase (Sigma, St. Louis, MO, USA) in PBS (pH 5.0) for $30 \mathrm{~min}$ at room temperature. After blocking nonspecific binding with 3\% bovine serum albumin in PBS, rabbit anti-type II collagen antibody (Novus Biologicals, Littleton, CO, USA) was incubated overnight at $4^{\circ} \mathrm{C}$. The next day, slides were washed in PBS and incubated with biotinylated antirabbit IgG antibody for $45 \mathrm{~min}$ at room temperature. Reaction was visualized by incubation with the avidin-biotinperoxidase reagent included in the Vectastain $A B C$ Kit (Vector Laboratories, Burlingame, CA, USA) followed by color development with 3-3' diaminobenzidinetetrahydrochloride (Dojindo, Kumamoto, Japan). Finally, the sections were counterstained with hematoxylin and mounted with coverslips. Cartilage tissue from mouse knee joint was used for control staining of collagen type II. Normal rabbit IgG was used as an isotype control.

\section{Western blot analysis}

For total protein extraction, pellets were homogenized and incubated with lysis buffer containing $20 \mathrm{mM}$ Tris$\mathrm{HCl}$ (pH 7.5), $150 \mathrm{mM} \mathrm{NaCl}, 1 \mathrm{mM} \mathrm{Na} 2$ EDTA, $1 \mathrm{mM}$ EGTA, 1\% NP-40, 0.1\% sodium dodecyl sulfate, $1 \mathrm{mM}$ $\mathrm{Na}_{3} \mathrm{VO}_{4}$, and protease inhibitor cocktail (Nacalai tesque, Kyoto, Japan) for $30 \mathrm{~min}$ on ice and centrifuged at $15,000 \mathrm{rpm}$ for $20 \mathrm{~min}$ at $4^{\circ} \mathrm{C}$. Proteins were separated by $10 \%$ sodium dodecyl sulfate-polyacrylamide gel electrophoresis (SDS-PAGE) and transferred onto a polyvinylidene fluoride (PVDF) membrane. The membranes were incubated overnight at $4^{\circ} \mathrm{C}$ with rabbit primary antibodies against type $1 \mathrm{PTH} / \mathrm{PTHrP}$ receptor (PTH1R) (LifeSpan Biosciences, Seattle, WA, USA), SRY-box9 (Sox9) (Millipore, Temecula, CA, USA), Runt-related transcription factor 2 (Runx2) (Novus Biologicals, Littleton, CO, USA) and $\beta$-actin (Novus Biologicals). The membranes were washed and incubated with horseradish peroxidase labeled anti-rabbit IgG (Kirkegaard and Perry Laboratories, Gaithersburg, MD, USA) for $60 \mathrm{~min}$ at room temperature. After a washing step, bands were visualized by ECL Prime Western blotting detection reagent (GE Healthcare, Piscataway, NJ, USA) and analyzed using a luminescent image analyzer equipped with a cooled CCD camera (LAS 1000, Fujifilm, Tokyo, Japan).

\section{Total RNA isolation and RT-PCR}

Total RNA was isolated from homogenized pellets using Trizol reagent (Invitrogen, Carlsbad, CA, USA). RNA was quantified by measuring absorbance at $260 \mathrm{~nm}$, and the quality was assessed by determining the $260 / 280 \mathrm{~nm}$ absorbance ratio. First-strand cDNA synthesis was performed with $0.5 \mu \mathrm{g}$ or $1 \mu \mathrm{g}$ total RNA in a total volume of $20 \mu \mathrm{l}$ using an iScript $\mathrm{t}^{\mathrm{mo}}$ advanced cDNA synthesis kit (BIO-RAD, Richmond, CA, USA). Gene expressions of collagen type II $\alpha 1$ chain (Col2a1), collagen type $\mathrm{X} \alpha 1$ chain (Col10a1), collagen type I $\alpha 1$ chain (Col1a1), Sox9, and PTH1R were examined with quantitative real-time PCR. The primers used in this study were listed in Table 1. Quantitative real-time PCR was carried out using SsoAdvanced ${ }^{\mathrm{m}}$ SYBR Green supermix (BIO-RAD) 
Table 1 Primers used for real-time RT-PCR

\begin{tabular}{lll}
\hline Gene & Direction & Sequences (5'-3') $^{\prime}$ \\
\hline Sox9 & Forward & TACGACTGGACGCTGGTGC \\
Cox9 & Reverse & CCGTTCTTCACCGACTTCCTCC \\
Col2a1 & Forward & CTGACCTGACCTGATGATACC \\
Col10a1 & Reverse & CACCAGATAGTTCCTGTCTCC \\
Col10a1 & Forward & CGAGGTATGCTTGATCTG \\
Col1a1 & Reverse & GACAGTCCAGTTCTTCAT \\
Col1a1 & Forward & TGACTGGAAGAGCGGAGAGT \\
PTH1R & Reverse & TCTCTCCAAACCAGACGTGC \\
PTH1R & Forward & CTCCTTCTCTGCTGCCCAGT \\
GAPDH & Reverse & TGCTGTGTGCAGAACTTCCT \\
GAPDH & Forward & TGAAGCAGGCATCTGAGGG \\
\hline
\end{tabular}

on a CFX96 ${ }^{\text {tin }}$ real-time PCR detection system (BIORAD) in a 20- $\mu$ l reaction volume. Expression of gene of interest was normalized to GAPDH expression.

\section{Statistical analysis}

All experiments were repeated at least three independent times. All data are presented as the mean \pm SEM. The analysis was done using SigmaStat 3.5 software (Systat Software Inc., Richmond, CA, USA). The nonparametric Kruskal-Wallis test was used to test for significant differences among the test groups. When a significant difference was detected, Steel's post hoc test was performed to compare each of the treatments with a control. An adjusted $P$ value $<0.05$ was considered statistically significant.

\section{Results}

\section{Histological findings}

Chondrogenic differentiation was confirmed with Alcian Blue staining for proteoglycan synthesis. Positive staining with Alcian Blue was identified in all treatment groups (Figure 1A,B,C,D,E). Among the groups, stronger staining was observed with 1 and $10 \mathrm{nM} \mathrm{PTH}$, whereas less intense staining was seen with $100 \mathrm{nM} \mathrm{PTH}$. Regarding cellular morphology, sections from cells treated with 10 nM PTH exhibited more chondrocyte-like cells with large round nuclei than cells treated with $100 \mathrm{nM}$ PTH. To further address chondrogenic differentiation, we examined the deposition of type II collagen, which is a major component of the cartilage extracellular matrix (Figure 1F,G,H,I,J). Expression of type II collagen was partially localized in $0 \mathrm{nM}$ PTH control. Improved expression was found in $10 \mathrm{nM} \mathrm{PTH}$. In contrast, almost negative expression was shown in $100 \mathrm{nM}$ PTH.

\section{Effect of PTH on protein expression in chondrogenic differentiation}

Protein expressions of PTH1R, Sox9, and Runx2 were detected by Western blotting (Figure 2). Positive expression

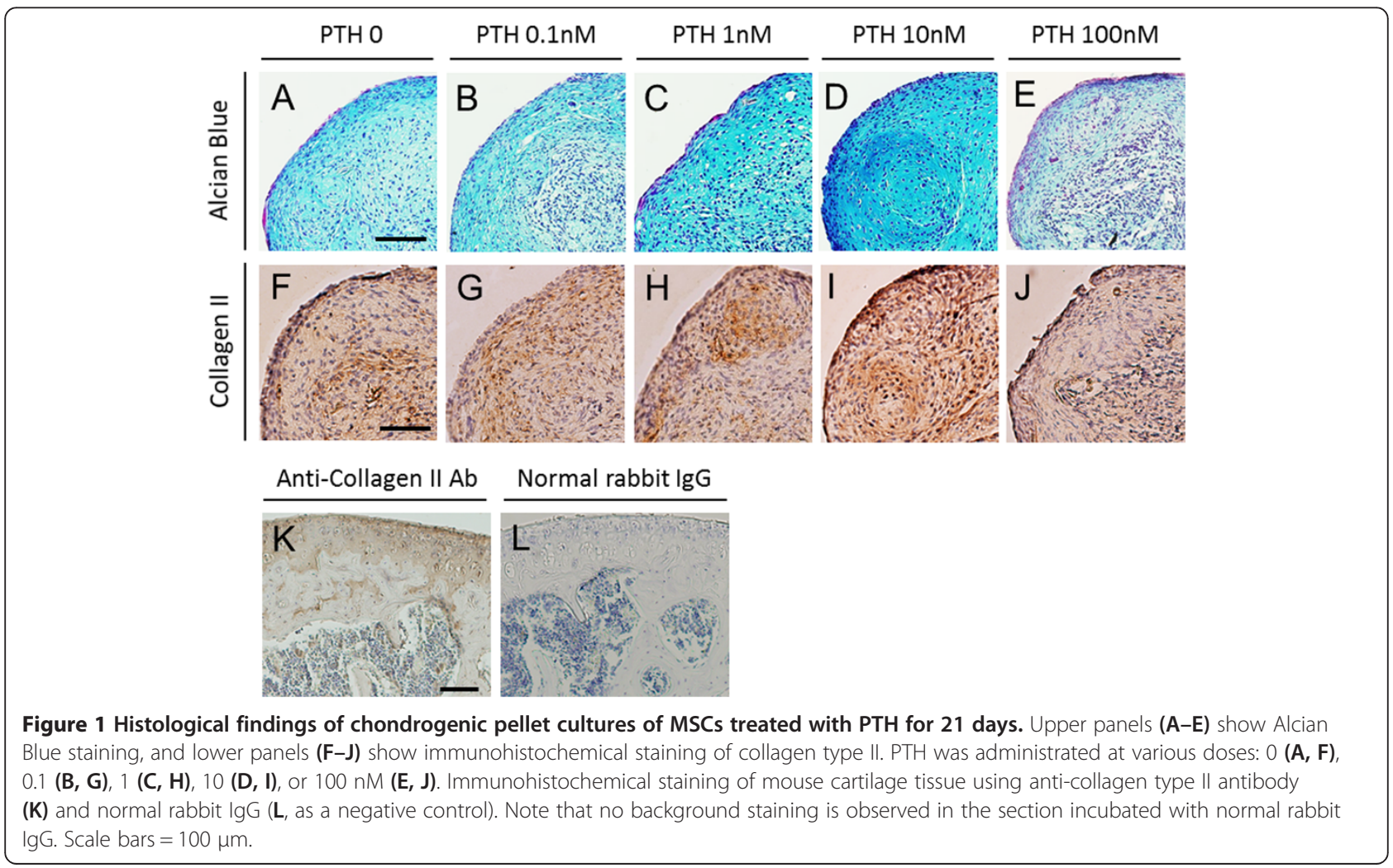




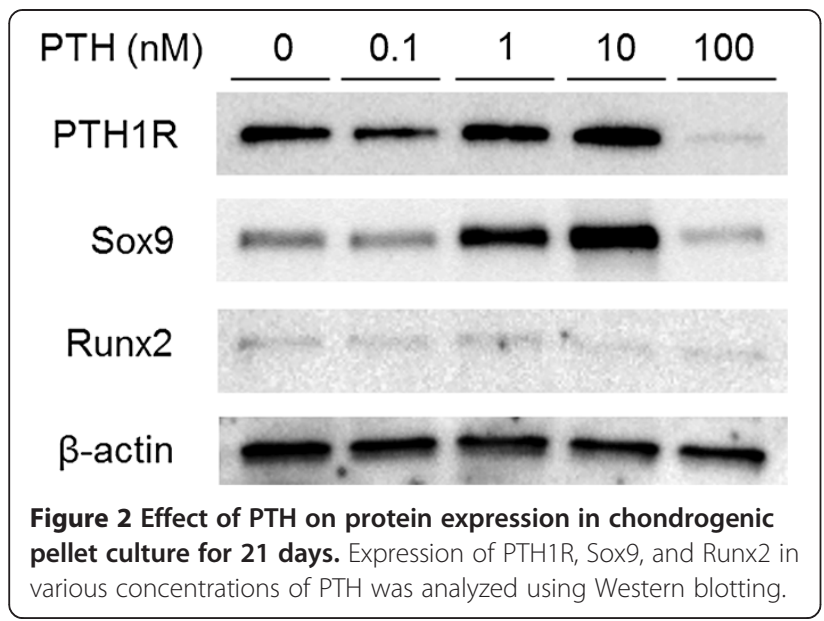

of PTH receptor was confirmed in $0-10 \mathrm{nM} \mathrm{PTH,}$ whereas the intensity was remarkably reduced in $100 \mathrm{nM}$ PTH. Protein expression of Sox9, a master regulator of chondrogenesis, was identified 3 weeks after chondrogenic differentiation from MSCs. Strong bands were present in 1 and $10 \mathrm{nM} \mathrm{PTH}$ and less intense one in 100 nM. Runx2, a transcription factor that promotes chondrocyte hypertrophy, was not intensely expressed in any PTH concentration.

\section{Effect of PTH on collagen expression in early stage of chondrogenic differentiation}

To determine whether PTH modulates the early stage of chondrogenic differentiation of MSCs, gene expression of type II collagen as a marker of chondrogenesis was analyzed when cells were treated with various doses of $\mathrm{PTH}$ (Figure 3A). Relative mRNA expression of Col2a1 was significantly reduced with $100 \mathrm{nM} \mathrm{PTH}$ at days 3,7 , and $21(P<0.05$, vs. $0 \mathrm{nM} \mathrm{PTH})$. In contrast, treatment with 1 and $10 \mathrm{nM}$ PTH resulted in significantly increased expression of Col2a1 at days 7 and $21(P<0.05$, vs. $0 \mathrm{nM}$ PTH). To assess the phenotypic change of hypertrophy during chondrogenesis of MSCs, gene expression of type $\mathrm{X}$ collagen as a marker of chondrogenic hypertrophy was also examined (Figure 3B). Relative mRNA expression of Col10a1 was not significantly changed with different doses of PTH at days 3,7 , and 21 . To further characterize the effect of PTH on chondrogenic differentiation of MSCs, gene expression of type I collagen as a marker of hypertrophic or osteogenic differentiation was investigated (Figure 3C). We observed no significant difference in relative mRNA expression levels of Col1a1 at days 3,7 , and 21 among the various dose groups.

\section{Effect of PTH on activation of Sox9 and PTH receptor during chondrogenic differentiation of MSCs}

To assess the effect of PTH on the key transcription factor involved in chondrogenic differentiation, gene expression
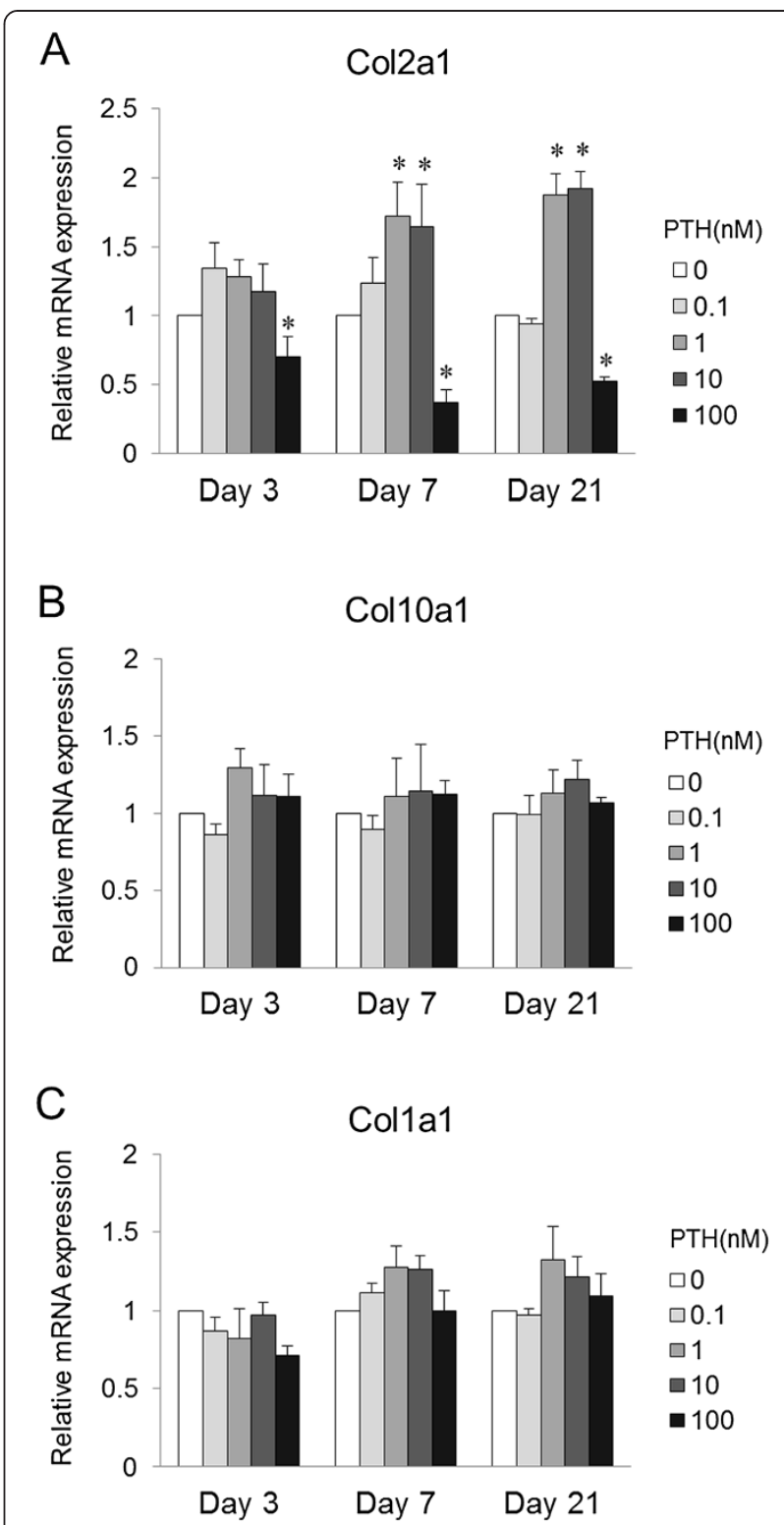

Figure 3 Effect of PTH on collagen expression in chondrogenic pellet culture for $\mathbf{3}, \mathbf{7}$, and $\mathbf{2 1}$ days. Relative mRNA levels of Col2a1 (A), Col10a1 (B), and Col1a1 (C) following PTH treatment are compared with expression in the control $(0 \mathrm{nM} \mathrm{PTH})(n=8$ for each dose). ${ }^{*} P<0.05$ vs. control group (Steel's test).

of Sox9 was analyzed (Figure 4A). Relative mRNA expression of Sox 9 was significantly diminished in the presence of $100 \mathrm{nM}$ PTH after days 3 and $21(P<0.05$, vs. $0 \mathrm{nM}$ $\mathrm{PTH})$. In contrast, significantly increased levels of Sox9 were seen with $0.1 \mathrm{nM} \mathrm{PTH}$ at day 7 , and 1 and $10 \mathrm{nM}$ PTH at days 7 and $21(P<0.05$, vs. 0 nM PTH). These expression patterns of Sox 9 among the various doses were similar to those of Col2a1. To determine if the receptor is upregulated in response to $\mathrm{PTH}$ administration, gene expression of the PTH receptor was examined (Figure 4B). Relative mRNA expression of PTH1R was significantly 


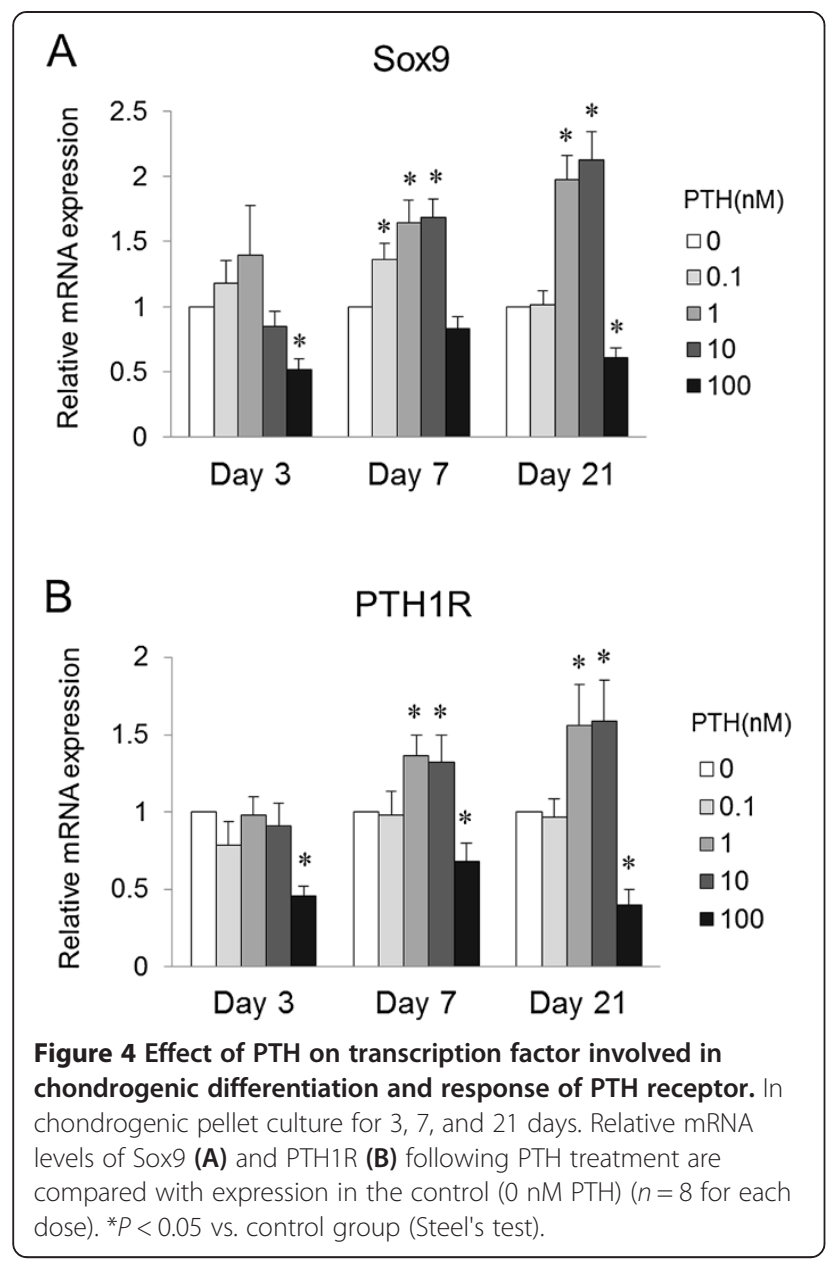

decreased with $100 \mathrm{nM}$ PTH at days 3,7 , and $21(P<0.05$, vs. $0 \mathrm{nM}$ PTH). In contrast, PTH1R was significantly increased with 1 and $10 \mathrm{nM}$ PTH at days 7 and $21(P<0.05$, vs. $0 \mathrm{nM}$ PTH). The expression patterns for PTH1R were very similar to those for Sox 9 and Col2a1.

\section{Discussion}

The present study demonstrated that chondrogenic differentiation of MSCs was modulated by PTH. The results revealed that PTH has opposite effects on chondrogenesis when administered at different concentrations. Namely, low to moderate concentrations of PTH promoted chondrogenic differentiation of MSCs, whereas chondrogenesis of MSCs was inhibited and not stimulated by a higher concentration of PTH.

This study was intended to test the hypothesis that PTH has a stimulatory effect on chondrogenic differentiation. An effect on induction of chondrogenesis with increased collagen type II was previously confirmed using a single concentration of PTH in growth plate chondrocytes [13] and MSCs from osteoarthritis patients [15]. In contrast, the inhibitory function of PTH on chondrocyte hypertrophy has been shown with reduced expression of collagen type $\mathrm{X}$ under conditions that promote chondrogenic differentiation $[15,16]$. The constitutive expression of the PTH/PTHrP receptor in a bone morphogenetic protein-dependent differentiation system leads to a marked stimulation of chondrogenic and osteogenic development, whereas permanent application of the ligand $\mathrm{PTH}(1-34)$ results in opposite responses by stimulating the early and suppressing the late stages of osteo-/chondrogenic development [17]. These contrasting effects of PTH(1-34) on osteogenic and chondrocytic development seem to depend on the cellular state of differentiation. Our results were partially consistent with those previous reports. However, different from previous reports, we observed that expression of both Col2a1 and PTH1R was suppressed by a higher concentration of PTH. To our knowledge, no supportive studies have been published showing that the response to $\mathrm{PTH}$ during chondrogenic differentiation is opposite depending on a lower or higher concentration. Therefore, the modulatory effect of PTH on chondrogenic differentiation is likely to remain controversial.

PTH and PTHrP show homology in the aminoterminal (1-34) peptide fragments with high-affinity binding to PTH1R. Biological responses elicited by either ligand through this common PTH1R are largely indistinguishable, at least with regard to mineral ion homeostasis [18]. According to Weiss and colleagues [19], adding $0.1 \mathrm{ng} / \mathrm{mL}$ of PTHrP beginning on day 21 could suppress collagen type $\mathrm{X}$ deposition without any negative effects on chondrogenic differentiation, whereas higher concentrations (10 or $100 \mathrm{ng} / \mathrm{mL}$ ) or earlier treatment (from day 0 ) would lead to the suppression of chondrogenesis. These contradictory effects of PTHrP on chondrogenic differentiation seem to be applicable to PTH on the basis of high similarity in the biological function [20]. Physicians may be interested in PTH rather than PTHrP because the former is currently available for clinical application. Therefore, several issues regarding the efficacy of PTH administration for successful cartilage repair need to be investigated further, including optimization of the concentration, treatment timing, and delivery method. The advantage of this study is that the investigations included a concentration-response range and examination of changes in expression of the exact genes.

The transcription factor Sox9 has been demonstrated to be a master regulator of the differentiation of mesenchymal cells into chondrocytes [21,22]. The TGF- $\beta$ signal plays an essential role to induce primary chondrogenesis [4,23], which is mediated by up-regulation of Sox9 [24]. Furthermore, Sox9 is a target of PTH/PTHrP receptor signaling to maintain the chondrocyte phenotype and inhibit their maturation to hypertrophic chondrocytes in the growth plate [25]. Our results support the idea of a PTH/ PTHrP receptor signal-dependent increase in Sox9 expression during chondrogenic differentiation from MSCs. 
This study has several limitations including the concentration and timing for administration of PTH. Physiological PTH concentrations are much lower than those used in this study. However, in a number of in vitro studies examining the efficacy of $\mathrm{PTH}$, the concentration tested is usually out of therapeutic ranges $[9,12,13,15,16]$. The response to PTH administration increases in a concentration-dependent manner, and the minimum effective concentration is higher than physiological levels $[13,26]$. Therefore, we have chosen concentrations that significantly altered the cellular response and that showed the expected efficacy. The ability to reflect clinical relevance with cell culture models is difficult due to the lack of physiological conditions once cells are isolated from tissues and organs. The question is whether the output response is supportive of our understanding of the biology that will lead to decisions regarding translation of appropriate concentrations for assessment in human clinical testing. Furthermore, the relationship between the timing of exposure and the efficacy is unclear because PTH was continuously administered throughout the experimental period. For clinical use, PTH is intermittently administered when utilized for bone anabolic effects. Whether intermittent administration rather than continuous administration is effective for cartilage induction remains to be determined. This point is especially important for direct administration for therapeutic use. Further studies are required to extrapolate the translatable efficacy and safety in humans. For current therapeutic application, indirect treatment of human organ systems ex vivo, such as treatment prior to cell implantation, seems rational.

\section{Conclusions}

This study provides insight into the modulatory effect of PTH on chondrogenic differentiation from MSCs. Ideal repair of injured cartilage involves replacement with hyaline cartilage and prevention of osteoarthritic changes. Several animal studies have shown that PTH has therapeutic potential for cartilage regeneration and protection as well as inhibition of progression of osteoarthritis $[9,10,14]$. PTH $(1-34)$ has a stimulatory effect on bone formation with intermittent administration and is currently used as an anabolic drug for treatment of osteoporosis. Based on clinical experience with the efficacy and safety of PTH for bone metabolism, PTH may also be clinically useful for cartilage repair.

\section{Competing interests}

The authors declare that they have no competing interests.

\section{Authors' contributions}

YZ, KK, and TS conceived and developed the study design. YZ and KK performed data acquisition and analysis. $Y Z$ and KK drafted the manuscript. All authors read and approved the final manuscript.

\section{Acknowledgements}

The authors thank Kimi Ishikawa for the help with sample preparation. This work was supported in part by a Grant-in-Aid for Scientific Research from the Ministry of Education, Culture, Sports, Science and Technology of Japan (\#25462347).

Received: 8 March 2014 Accepted: 18 July 2014

Published: 1 August 2014

\section{References}

1. Muschler GF, Midura RJ: Connective tissue progenitors: practical concepts for clinical applications. Clin Orthop Relat Res 2002, 395:66-80.

2. Muschler GF, Nakamoto C, Griffith LG: Engineering principles of clinical cell-based tissue engineering. J Bone Joint Surg Am 2004, 86-A:1541-1558.

3. Caplan Al: Mesenchymal stem cells. J Orthop Res 1991, 9:641-650.

4. Pittenger MF, Mackay AM, Beck SC, Jaiswal RK, Douglas R, Mosca JD, Moorman MA, Simonetti DW, Craig S, Marshak DR: Multilineage potential of adult human mesenchymal stem cells. Science 1999, 284:143-147.

5. Johnstone B, Hering TM, Caplan Al, Goldberg VM, Yoo JU: In vitro chondrogenesis of bone marrow-derived mesenchymal progenitor cells. Exp Cell Res 1998, 238:265-272.

6. Sekiya I, Larson BL, Vuoristo JT, Reger RL, Prockop DJ: Comparison of effect of BMP-2, -4 , and -6 on in vitro cartilage formation of human adult stem cells from bone marrow stroma. Cell Tissue Res 2005, 320:269-276.

7. Richardson SM, Hoyland JA, Mobasheri R, Csaki C, Shakibaei M, Mobasheri A: Mesenchymal stem cells in regenerative medicine: opportunities and challenges for articular cartilage and intervertebral disc tissue engineering. J Cell Physiol 2010, 222:23-32.

8. Wakitani S, Imoto K, Yamamoto T, Saito M, Murata N, Yoneda M: Human autologous culture expanded bone marrow mesenchymal cell transplantation for repair of cartilage defects in osteoarthritic knees. Osteoarthritis Cartilage 2002, 10:199-206.

9. Chang JK, Chang LH, Hung SH, Wu SC, Lee HY, Lin YS, Chen CH, Fu YC, Wang GJ, Ho ML: Parathyroid hormone 1-34 inhibits terminal differentiation of human articular chondrocytes and osteoarthritis progression in rats. Arthritis Rheum 2009, 60:3049-3060.

10. Sampson ER, Hilton MJ, Tian Y, Chen D, Schwarz EM, Mooney RA, Bukata SV, O'Keefe RJ, Awad H, Puzas JE, Rosier RN, Zuscik MJ: Teriparatide as a chondroregenerative therapy for injury-induced osteoarthritis. Sci Trans/ Med 2011, 3:101ra193.

11. Harrington EK, Coon DJ, Kern MF, Svoboda KK: PTH stimulated growth and decreased Col-X deposition are phosphotidylinositol-3,4,5 triphosphate kinase and mitogen activating protein kinase dependent in avian sterna. Anat Rec (Hoboken) 2010, 293:225-234.

12. Harrington EK, Roddy GW, West R, Svoboda KK: Parathyroid hormone/ parathyroid hormone-related peptide modulates growth of avian sternal cartilage via chondrocytic proliferation. Anat Rec (Hoboken) 2007, 290:155-167.

13. Ishikawa Y, Wu LN, Genge BR, Mwale F, Wuthier RE: Effects of calcitonin and parathyroid hormone on calcification of primary cultures of chicken growth plate chondrocytes. J Bone Miner Res 1997, 12:356-366.

14. Kudo S, Mizuta H, Takagi K, Hiraki Y: Cartilaginous repair of full-thickness articular cartilage defects is induced by the intermittent activation of PTH/PTHrP signaling. Osteoarthritis Cartilage 2011, 19:886-894.

15. Mwale F, Yao G, Ouellet JA, Petit A, Antoniou J: Effect of parathyroid hormone on type $X$ and type II collagen expression in mesenchymal stem cells from osteoarthritic patients. Tissue Eng Part A 2010, 16:3449-3455.

16. Zerega B, Cermelli S, Bianco P, Cancedda R, Cancedda FD: Parathyroid hormone $[\mathrm{PTH}(1-34)]$ and parathyroid hormone-related protein $[\mathrm{PTHrP}(1-34)]$ promote reversion of hypertrophic chondrocytes to a prehypertrophic proliferating phenotype and prevent terminal differentiation of osteoblastlike cells. J Bone Miner Res 1999, 14:1281-1289.

17. Hollnagel A, Ahrens M, Gross G: Parathyroid hormone enhances early and suppresses late stages of osteogenic and chondrogenic development in a BMP-dependent mesenchymal differentiation system (C3H10T1/2). J Bone Miner Res 1997, 12:1993-2004.

18. Mannstadt M, Juppner H, Gardella TJ: Receptors for PTH and PTHrP: their biological importance and functional properties. Am J Physiol 1999, 277:F665-F675.

19. Weiss S, Hennig T, Bock R, Steck E, Richter W: Impact of growth factors and PTHrP on early and late chondrogenic differentiation of human mesenchymal stem cells. J Cell Physiol 2010, 223:84-93. 
20. Zhang W, Chen J, Zhang S, Ouyang HW: Inhibitory function of parathyroid hormone-related protein on chondrocyte hypertrophy: the implication for articular cartilage repair. Arthritis Res Ther 2012, 14:221.

21. Akiyama H, Chaboissier MC, Martin JF, Schedl A, de Crombrugghe B: The transcription factor Sox 9 has essential roles in successive steps of the chondrocyte differentiation pathway and is required for expression of Sox5 and Sox6. Genes Dev 2002, 16:2813-2828.

22. Bi W, Deng JM, Zhang Z, Behringer RR, de Crombrugghe B: Sox9 is required for cartilage formation. Nat Genet 1999, 22:85-89.

23. Heng $B C$, , Cao $T$, Lee EH: Directing stem cell differentiation into the chondrogenic lineage in vitro. Stem Cells 2004, 22:1152-1167.

24. Furumatsu T, Tsuda M, Taniguchi N, Tajima Y, Asahara H: Smad3 induces chondrogenesis through the activation of SOX9 via CREB-binding protein/p300 recruitment. J Biol Chem 2005, 280:8343-8350.

25. Huang W, Chung UI, Kronenberg HM, de Crombrugghe B: The chondrogenic transcription factor Sox 9 is a target of signaling by the parathyroid hormone-related peptide in the growth plate of endochondral bones. Proc Natl Acad Sci U S A 2001, 98:160-165.

26. Rickard DJ, Wang FL, Rodriguez-Rojas AM, Wu Z, Trice WJ, Hoffman SJ, Votta B, Stroup GB, Kumar S, Nuttall ME: Intermittent treatment with parathyroid hormone (PTH) as well as a non-peptide small molecule agonist of the PTH1 receptor inhibits adipocyte differentiation in human bone marrow stromal cells. Bone 2006, 39:1361-1372.

doi:10.1186/s13018-014-0068-5

Cite this article as: Zhang et al:: Effect of parathyroid hormone on early chondrogenic differentiation from mesenchymal stem cells. Journal of Orthopaedic Surgery and Research 2014 9:68.

\section{Submit your next manuscript to BioMed Central and take full advantage of:}

- Convenient online submission

- Thorough peer review

- No space constraints or color figure charges

- Immediate publication on acceptance

- Inclusion in PubMed, CAS, Scopus and Google Scholar

- Research which is freely available for redistribution 